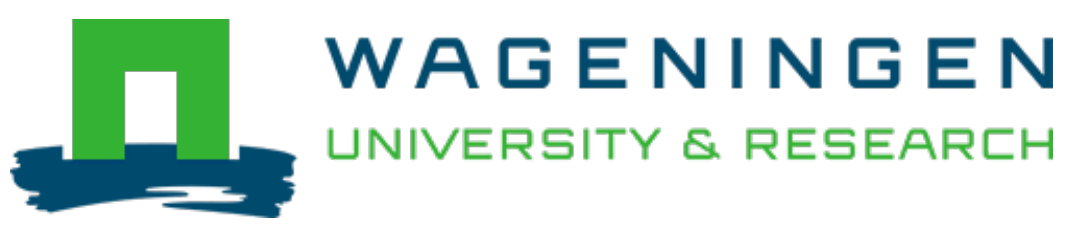

\title{
Plant architectural responses in simultaneous maize/soybean strip intercropping do not lead to a yield advantage
}

\author{
Annals of Applied Biology \\ Li, Shuangwei; Evers, Jochem B.; Werf, Wopke; Wang, Ruili; Xu, Zhaoli et al \\ https://doi.org/10.1111/aab.12610
}

This article is made publicly available in the institutional repository of Wageningen University and Research, under the terms of article $25 \mathrm{fa}$ of the Dutch Copyright Act, also known as the Amendment Taverne. This has been done with explicit consent by the author.

Article 25 fa states that the author of a short scientific work funded either wholly or partially by Dutch public funds is entitled to make that work publicly available for no consideration following a reasonable period of time after the work was first published, provided that clear reference is made to the source of the first publication of the work.

This publication is distributed under The Association of Universities in the Netherlands (VSNU) 'Article $25 \mathrm{fa}$ implementation' project. In this project research outputs of researchers employed by Dutch Universities that comply with the legal requirements of Article $25 \mathrm{fa}$ of the Dutch Copyright Act are distributed online and free of cost or other barriers in institutional repositories. Research outputs are distributed six months after their first online publication in the original published version and with proper attribution to the source of the original publication.

You are permitted to download and use the publication for personal purposes. All rights remain with the author(s) and / or copyright owner(s) of this work. Any use of the publication or parts of it other than authorised under article $25 \mathrm{fa}$ of the Dutch Copyright act is prohibited. Wageningen University \& Research and the author(s) of this publication shall not be held responsible or liable for any damages resulting from your (re)use of this publication.

For questions regarding the public availability of this article please contact openscience.library@,wur.nl 


\title{
Plant architectural responses in simultaneous maize/soybean strip intercropping do not lead to a yield advantage
}

\author{
Shuangwei $\mathrm{Li}^{1,2} \odot$ | Jochem B. Evers ${ }^{2}$ | Wopke van der Werf ${ }^{2} \quad$ | Ruili Wang ${ }^{3}$ | \\ Zhaoli Xu ${ }^{4}$ | Yan Guo ${ }^{1}$ | Baoguo $\mathrm{Li}^{1}$ | Yuntao $\mathrm{Ma}^{1}$
}

${ }^{1}$ College of Land Science and Technology, China Agricultural University, Beijing, China

${ }^{2}$ Centre for Crop Systems Analysis, Wageningen University, Wageningen, the Netherlands

${ }^{3}$ Inner Mongolia Autonomous Region Biotechnology Research Institute, Huhehaote, China

${ }^{4}$ Yunnan Academy of Tobacco Agricultural Sciences, Kunming, China

\section{Correspondence}

Yuntao Ma, College of Land Science and Technology, China Agricultural University, Beijing 100193, China.

Email: yuntao.ma@cau.edu.cn

Jochem B. Evers, Centre for Crop Systems Analysis, Wageningen University, 6708 PB Wageningen, the Netherlands.

Email: jochem.evers@wur.nl

Funding information

China Scholarship Council, Grant/Award Number: CSC201706350202; National Key Research and Development Program of China, Grant/Award Number: 2016YFD0300202; 31000671; Science and Technology projects from Yunnan, Grant/Award Number: 2017YN07

\begin{abstract}
Maize/soybean strip intercropping is a commonly used system throughout China with high crop yields at reduced nutrient input compared to sole maize. Maize is the taller crop, and due to its dominance in light capture over soybean in the intercrop, maize is expected to outperform maize in sole cropping. Conversely, soybean is the subordinate crop and intercropped soybean plants are expected to perform worse than sole soybean. Crop plants show plastic responses in plant architecture to their growing conditions to forage for light and avoid shading. There is little knowledge on plant architectural responses to growing conditions in simultaneous (non-relay) intercropping and their relationship to species yields. A two-year field experiment with two simultaneous maize/soybean intercropping systems with narrow and wide strips was conducted to characterise architectural traits of maize and soybean plants grown as intercrop and sole crops. Intercropped maize plants, especially those in border rows, had substantially greater leaf area, biomass and yield than maize plants in sole crops. Intercropped soybean plants, especially those in border rows, had lower leaf area, biomass and yield than sole soybean plants. Overall intercrop performance was similar to that of sole crops, with the land equivalent ratio (LER) being only slightly greater than one (1.03-1.08). Soybean displayed typical shade avoidance responses in the intercrop, such as greater internode elongation and changes in specific leaf area, but these responses could not overcome the consequences of the competition with the taller maize plants. Therefore, in contrast to relay intercrop systems, in the studied simultaneous maize/soybean system, plastic responses did not contribute to practically relevant increases in resource capture and yield at whole system (i.e., intercrop) level.
\end{abstract}

\section{KEYWORDS}

architectural response, border row effect, growth, intercropping, land equivalent ratio

\section{1 | INTRODUCTION}

Intercropping is the practice of growing two or more crops in the same field for a significant part of their growing period (Brooker et al., 2015; Vandermeer, 1989). Intercropping is often practiced by farmers to obtain greater production from the same land than can be obtained using sole crops; moreover, intercropping can also be used to obtain the same yields as sole crops but with lower inputs (Exner, Davidson, Ghaffarzadeh, \& Cruse, 1999). Furthermore, intercropping provides a number of ecosystem services, due to its positive effects on soil quality (Cong et al., 2015) and control of wind erosion (Chen, Cui, Wu, Zhao, \& Sun, 2010), pests (Liang et al., 2016), plant diseases 
(Boudreau, 2013) and weeds (Liebman \& Dyck, 1993; Saucke \& Ackermann, 2006).

Intercropping in China is predominantly practiced in the form of strip intercropping, in which alternating strips of two crop species are grown side by side (Li, Zhang, \& Zhang, 2013; Yu, Stomph, Makowski, \& van der Werf, 2015). A crop strip is composed by two or more rows of the same species. For optimal performance, the strips are kept wide enough to avoid that the dominant species completely overgrows the subordinate species, while permitting separate cultivation. On the other hand, the strips should be narrow enough for the crops to have interactions that maximise complementary resource capture. According to Grime (1987), dominant species are few in number, tall and more expansive in morphology and produce high quantities of biomass and subordinate species are generally more numerous, but smaller in stature and form a low proportion of the total community biomass. Complementarity arises if different species capture resources at a different time or place or from a different source, for example, nitrogen from the soil or from the air (Li et al., 2013). As a result of complementarity, total resource capture can be enhanced, increasing yield (e.g., L. Zhang et al., 2008). Complementarity can exist in the way that intercropped species acquire light (Gao et al., 2010; Q. Wang et al., 2015; L. Zhang et al., 2008), water (Mao et al., 2012; Z. Wang, Wu, Zhao, Gao, \& Chen 2015) and nutrients (F. Zhang \& $\mathrm{Li}, 2003)$. All three complementarities can exist simultaneously and reinforce each other (Evers, van der Werf, Stomph, Bastiaans, \& Anten, 2019). Strong complementarity in resource capture and yield increase is obtained in relay intercrops, that is, intercrops in which the sowing and harvesting periods of the species differ such that interspecific competition for resources occurs only during the co-growth period (F. Zhang \& Li, 2003).

Maize (Zea mays L.)/soybean [Glycine max (L.) Merr.] intercropping is a cereal/legume intercrop system in which maize experiences reduced competition for nitrogen because soybean can fix nitrogen from the air in root nodules that contain the nitrogen fixing symbiotic Rhizobium bacteria (Ahmed \& Rao, 1982; Echarte et al., 2011; Lv, Francis, Wu, Chen, \& Zhao, 2014). Furthermore, maize in intercrops with soybean captures additional light because it is taller than soybean; however, this goes at the expense of radiation capture by the soybean (Liu et al., 2017; Yang et al., 2014). In northeast China, due to the relatively short growing season, maize and soybean in intercrops are sown and harvested at the same time, whereas in warmer regions such as Sichuan, relay intercropping is more common (Du et al., 2018). Temporal complementarity may exist in simultaneous intercropping due to different growth patterns and temporal trends in resource need of different species. However, in contrast to relay intercrops, species interactions exist over the whole growing period in simultaneous intercropping. There is little information on the potential for complementary resource capture, especially for light, in relation to architectural plant traits, such as growth rate, leaf size and area, and internode size in simultaneous intercropping. Before the possible relevance of trait plasticity in intercropping can be analysed using modelling (Zhu, van der Werf, Anten, Vos, \& Evers, 2015), the putative plastic responses first need to be characterised and quantified (Zhu et al., 2016).
Complementary resource capture in strip intercropping is mostly manifested in border rows, in which one species can take advantage of the resources left by another species that is competing less for these resources than conspecific plants (e.g., Gou, van Ittersum, Wang, van der Putten, \& van der Werf, 2016; Zhu et al., 2016). Plants may respond to the greater resource availability in intercropping by increased formation of organs that capture these resources. For instance, wheat plants in border rows with maize in relay intercropping form extra tillers with larger leaves because of little competition for light from the later sown neighbouring maize plants during the early growth of the wheat (Zhu et al., 2016). The architectural responses of wheat in wheat/maize relay strip intercropping increase its resource capture (Zhu et al., 2015) and support the yield increase in border rows and in the intercrop as a whole. Plants in the inner rows of the strips in a strip intercrop typically do not differ in resource acquisition, growth and yield from plants of the same species in a sole crop and they also do not usually show architectural differences with sole crop plants. In maize/soybean intercropping, border row effects on grain yield have been identified (Ghaffarzadeh, Préchac, \& Cruse, 1994; Lesoing \& Francis, 1999) but the architectural traits underlying these yield effects have not been characterised.

When simultaneously sown with maize, soybean is shaded by the taller maize plants. In general, plants show architectural responses to shade, such as increased internode length and greater specific leaf area that tend to increase the capture of the limiting light resource (Pierik \& De Wit, 2014). In relay intercropping with maize, soybean leaf area is usually reduced as a result of shading and reduced photosynthesis and biomass production (Ahmed et al., 2018; Yang et al., 2014, 2015). In a simultaneous intercrop with maize, the soybean has a better starting position with respect to competition for light than in relay intercropping in which soybean is sown after maize. There is little information about which architectural responses are shown by soybean in a simultaneous intercrop with maize, and whether those responses mitigate the effects of maize competition.

The overall aim of this study is, therefore, to characterise architectural plant responses to simultaneous maize/soybean intercropping. Based on the difference between maize and soybean in the strength of competition for light, we predict that maize will show responses that are associated with the greater light capture resulting from its taller stature (increased biomass growth, greater leaf area, and increased kernel number, kernel weight and yield). Plant height in intercropped maize could be smaller than in sole maize because of a reduced competition for light with neighbours. On the other hand, we predict that soybean will show responses that are associated with the shade avoidance syndrome (Pierik \& De Wit, 2014). These responses include longer internodes, thinner leaves and thinner stems. Furthermore, because of the reduced light capture and assimilation by soybean, we expect lower pod number, lower pod weight and lower yield. We expect the responses of maize to be strongest in wide strip intercropping, because this system maximises incoming light for the maize, especially in the border rows. We expect responses of soybean to be strongest in narrow strip intercropping, because of the stronger shading of soybean by maize in this system. Overall, we expect the 
strongest architectural responses in border rows. Furthermore, we expect that yield advantage of maize/soybean intercropping would be small in fertilised simultaneous intercropping, because complementarity for $\mathrm{N}$ uptake would be unimportant due to fertiliser input, while complementarity for light capture would be small due to simultaneous sowing. On the other hand, uncertainty exists regarding this prediction of limited complementarity because light use efficiency could be modulated by a higher diffuse radiation in intercropped soybean than in sole soybean (Ofori \& Stern, 1987), while complementarity for water acquisition can also not be ruled out a priori (Gou et al., 2018; Morris \& Garrity, 1993). Thus, our measurements on yield are in part related to the question whether reasoning on the basis of light interception is supported by yield data. These predictions were tested in field studies comparing plant growth, yield, yield components and architectural traits in simultaneous maize/soybean intercrops grown in wide or narrow strips, and the corresponding sole crops.

\section{2 | MATERIALS AND METHODS}

\subsection{Field experiments}

Field experiments were conducted in 2017 and 2018 at Lishu, Jilin, China $\left(43^{\circ} 16^{\prime} \mathrm{N}\right.$ and $\left.124^{\circ} 26^{\prime} \mathrm{E}\right)$. The region is a typical semi-humid area with $573 \mathrm{~mm}$ average annual precipitation, $5.9^{\circ} \mathrm{C}$ annual mean temperature, $3,078^{\circ} \mathrm{C}$ annual cumulative temperature $\left(\geq 10^{\circ} \mathrm{C}\right)$ and 142 frostfree days. Most of the rain falls from June to September. The soil is a silty clay loam with a bulk density of $1.50 \mathrm{~g} \mathrm{~cm}^{-3}$, and a total nitrogen of $1.66 \mathrm{~g} \mathrm{~kg}^{-1}$, available phosphorus of $38 \mathrm{mg} \mathrm{kg}^{-1}$, available potassium of $144 \mathrm{mg} \mathrm{kg}^{-1}$ and a pH of 6.70 in the top soil $(0-30 \mathrm{~cm})$.

The experiments were set up as complete randomised block designs with four treatments and three replicates. Growth and yield of maize and soybean were compared between two intercropping patterns and the sole crops. The intercropping patterns were: (a) two rows of maize alternated with two rows of soybean (2:2 MS); and (b) three rows of maize alternated with six rows of soybean (3:6 MS) (Figure 1). In the 2:2 system, all rows were border rows. In the 3:6 MS system, there were two outer maize rows and one inner row, and two outer soybean rows and four inner rows. The border rows and inner rows were separately analysed. Row distance was $50 \mathrm{~cm}$ in all treatments, including the intercrops. Plant distance in the row was $20 \mathrm{~cm}$ for maize and $10 \mathrm{~cm}$ for soybean. Therefore, the plant density was 10 plants $\mathrm{m}^{-2}$ in sole maize and 20 plants $\mathrm{m}^{-2}$ in sole soybean. In intercrops, the relative density ( $R D$, density in the intercrop divided by sole crop plant density) for maize was 0.5 in 2:2 MS and 0.33 in 3:6 MS, while for soybean it was 0.5 in 2:2 MS and 0.67 in 3:6 MS. Plot size was $24 \mathrm{~m} \times 10 \mathrm{~m}$ in 2017 and $24 \mathrm{~m} \times 9 \mathrm{~m}$ in 2018 . The row orientation was approximately southeast-northwest in both years.

Maize cultivar "Zhengdan 958" and soybean cultivar "Jiyu 47" were sown on 11 May in 2017 and 10 May in 2018. There were 2-3 seeds per hole when sowing, and only one plant per seeding hole was maintained after emergence. Harvesting was on 25 September in 2017 and on 26 September in 2018, when grains were physiologically mature. Basal chemical fertiliser was applied in all plots and both years before sowing at a rate of $80 \mathrm{~kg} \mathrm{Nha}^{-1}, 52 \mathrm{~kg} \mathrm{P} \mathrm{ha}^{-1}$ and $83 \mathrm{~kg} \mathrm{~K} \mathrm{ha}^{-1}$. Two top dressings of $80 \mathrm{~kg} \mathrm{~N} \mathrm{ha}^{-1}$ each were applied to sole maize and intercropped maize at the V8 and V16 stages (i.e., eight and 16 leaves with collar visible). Urea, diammonium phosphate and potassium sulphate were used as sources of $\mathrm{N}, \mathrm{P}$ and $\mathrm{K}$, respectively. The experiments were rain-fed. Weeds were controlled by hand, and pests and diseases were controlled chemically according to farmers' practice. Meteorological data, including daily temperature, precipitation and PAR, during the growing season were obtained from a weather station (Rainroot, China) at the experimental site and calculated to monthly values (Table S1). (a) Sole Soybean

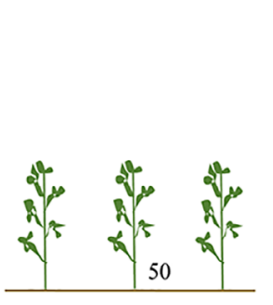

sole soybean (a), sole maize (b), narrow strip intercrop (2:2 MS) (c, two rows of maize alternated with two rows of soybean) and wide strip intercrop (3:6 MS) (d, three rows of maize alternated with six rows of soybean) (Unit: $\mathrm{cm}$ ). Plant distance in the row is $20 \mathrm{~cm}$ for maize and $10 \mathrm{~cm}$ for soybean. All rows in 2:2 MS are border rows. The 3:6 MS system has two outer maize rows (M1 and M3) and one inner row (M2), and two outer soybean rows ( $\mathrm{S} 1$ and S6) and four inner rows (S2, S3, S4 and S5) (b) Sole Maize

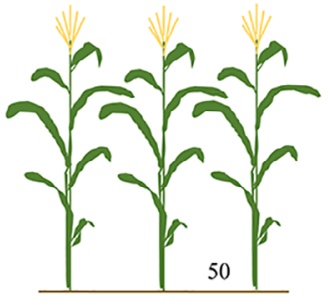

(d) 3:6 MS
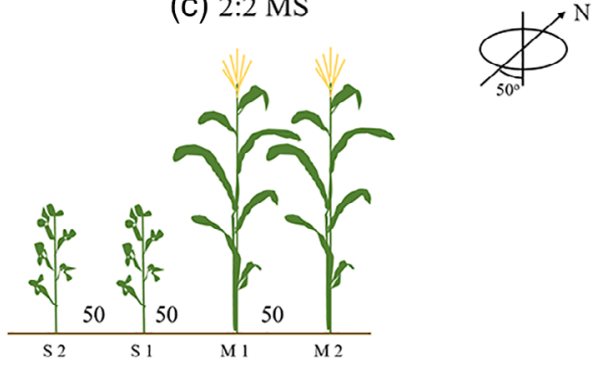

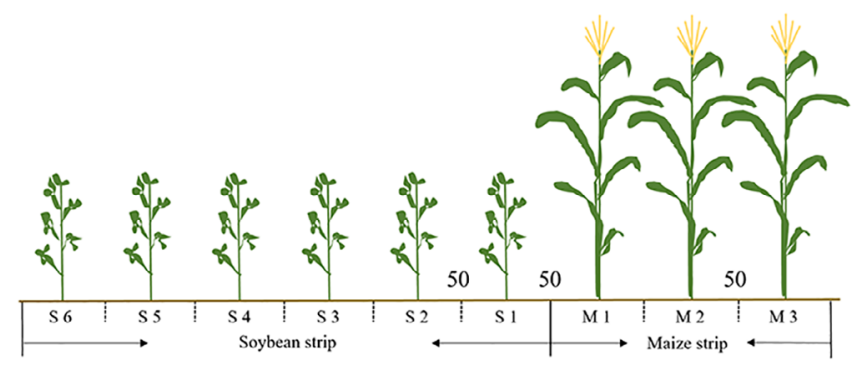




\section{2 | Measurements}

\subsection{1 | Leaf appearance}

Observations on leaf tip appearance were made every 3-7 days on both species in each treatment from plant emergence till the end of vegetative growth. Separate measurements were made for border rows and inner rows. We selected for this randomly six plants in one of the sole crop plots and six plants in each row of one strip in one plot for the two intercropping treatments. Thermal time $\left({ }^{\circ} \mathrm{Cd}\right)$ was calculated from weather station data, using a base temperature of $8^{\circ} \mathrm{C}$ for maize and $10^{\circ} \mathrm{C}$ for soybean (Major, Johnson, Tanner, \& Anderson, 1975; Ritchie \& NeSmith, 1991). Phyllochron (i.e., the thermal time between successive tip appearances) was estimated per plant as the slope of the linear regression of thermal time vs. leaf number $\left({ }^{\circ} \mathrm{Cd}\right.$ leaf $\left.^{-1}\right)$. Per treatment the average phyllochron was calculated.

\subsection{2 | Destructive measurements on plant architecture}

Destructive measurements on plant architecture, such as plant height, leaf size and internode size were made every 15 days in all replicates from 25 days after emergence. Two plants were sampled per plot in sole crops, and in the intercropping treatments two plants per row were sampled (one strip per species) to measure plant height, leaf area and leaf biomass. Sampled plants were selected randomly, which stand for the average level of plot, while keeping a distance of at least $1 \mathrm{~m}$ from gaps in the canopy from previous sampling. Plants were cut down from the soil surface to measure plant height. The base stem diameter, which is the diameter of the first rank from bottom to top, of both species and final internode length of soybean were measured at the maize R2 stage. Leaf area at each phytomer rank was measured using a LI-COR LI-3100 leaf area meter (LI-COR, Inc., NB, USA). When measuring the leaf area, it was recorded whether the leaf was mature or immature. Leaves were considered mature when the collar was visible (maize) or when its size did not change anymore after several measurements (soybean). Leaf samples were oven-dried at $105^{\circ} \mathrm{C}$ for $30 \mathrm{~min}$ and then at $70^{\circ} \mathrm{C}$ until a constant weight was reached. Leaf area and leaf biomass of mature leaves were used to calculate specific leaf area (SLA). Ear position was recorded as the rank of the node supporting the main ear. Pod position in soybean was recorded as the height $(\mathrm{cm})$ of the first rank that had seed-bearing pods.

\subsection{3 | Yield}

In 2017, grain yield was determined by harvesting $8 \mathrm{~m}^{2}$ (two rows, $8 \mathrm{~m}$ ) in each sole maize plot and $5 \mathrm{~m}^{2}$ (two rows, $5 \mathrm{~m}$ ) in each sole soybean plot, and $8 \mathrm{~m}$ for each maize row and $5 \mathrm{~m}$ for each soybean row in a central strip in each intercrop plot. Border strips of a plot were avoided in the sampling due to human impact. In 2018, $1 \mathrm{~m}^{2}$ (one row, $2 \mathrm{~m}$ ) per sole maize plot and $0.5 \mathrm{~m}^{2}$ (one row, $1 \mathrm{~m}$ ) per sole soybean plot were harvested to measure the grain yield. Two metres row length for maize and $1 \mathrm{~m}$ row length for soybean were harvested separately for each row in a central strip in each intercrop plot. Also here border strips of a plot were avoided in the sampling. All sample area in both years represented the average plant status in the plots. All grain samples were air-dried on a drying floor to a standard moisture content ( 14\%).

In 2017, 10 plants for maize and seven plants for soybean in each sample were randomly selected to determine the dry weight of grain and the whole plant in order to calculate the harvest index (grain dry biomass/aboveground dry matter). Using these plants, we determined yield components including grain number per plant, 100-grain weight and grain yield per meter row. In 2018, five plants in each sample were randomly selected to measure the yield components. The grain yield per meter row was calculated as the number of plants per metre row $\times$ grain number per plant $\times$ grain weight.

\section{3 | Data analysis}

Land equivalent ratio (LER) was used to quantify the yield advantage provided by intercropping (Rao \& Willey, 1980):

$$
L E R=L E R_{\mathrm{m}}+L E R_{\mathrm{s}}=\frac{Y_{\mathrm{m}}}{M_{\mathrm{m}}}+\frac{Y_{\mathrm{s}}}{M_{\mathrm{s}}}
$$

where $Y_{\mathrm{m}}$ and $Y_{\mathrm{s}}$ are the yields $\left(\mathrm{tha}^{-1}\right)$ of each species in intercropping, and $M_{m}$ and $M_{s}$ are yields $\left(t h^{-1}\right)$ for each species grown as a sole crop. $L E R_{\mathrm{m}}$ and $L E R_{\mathrm{s}}$ are partial LER values (relative yields) for each species. An LER value greater than 1 indicates a yield advantage for intercropping over sole cropping; generating the yields obtained in intercropping with sole crops would require a greater land area.

An index that quantifies the competitiveness of species in an intercrop is the index of aggressivity $A_{m s}$ (McGilchrist, 1965):

$$
A_{\mathrm{ms}}=A_{\mathrm{m}}-A_{\mathrm{s}}=\frac{L E R_{\mathrm{m}}}{R D_{\mathrm{m}}}-\frac{L E R_{\mathrm{s}}}{R D_{\mathrm{s}}},
$$

where $A_{m}$ and $A_{s}$ represent relative biomass or yield of individual plants in the intercrop compared to the sole crop for maize and soybean, respectively. $R D_{\mathrm{m}}$ and $R D_{\mathrm{s}}$ are the relative densities of maize and soybean in the intercrop, calculated as the ratio of the overall density of plants over the total intercrop area, divided by the density of the same species in the sole crop. We expect $A_{m}>1$ and $A_{s}<1$, and $A_{\mathrm{ms}}>0$, because maize is usually the dominant species in the maize/soybean system.

\subsection{Statistical analysis}

We used one-way analysis of variance (ANOVA) and least significant differences (LSD) tests in the "stats" and "agricolae" package of $\mathrm{R}$ 


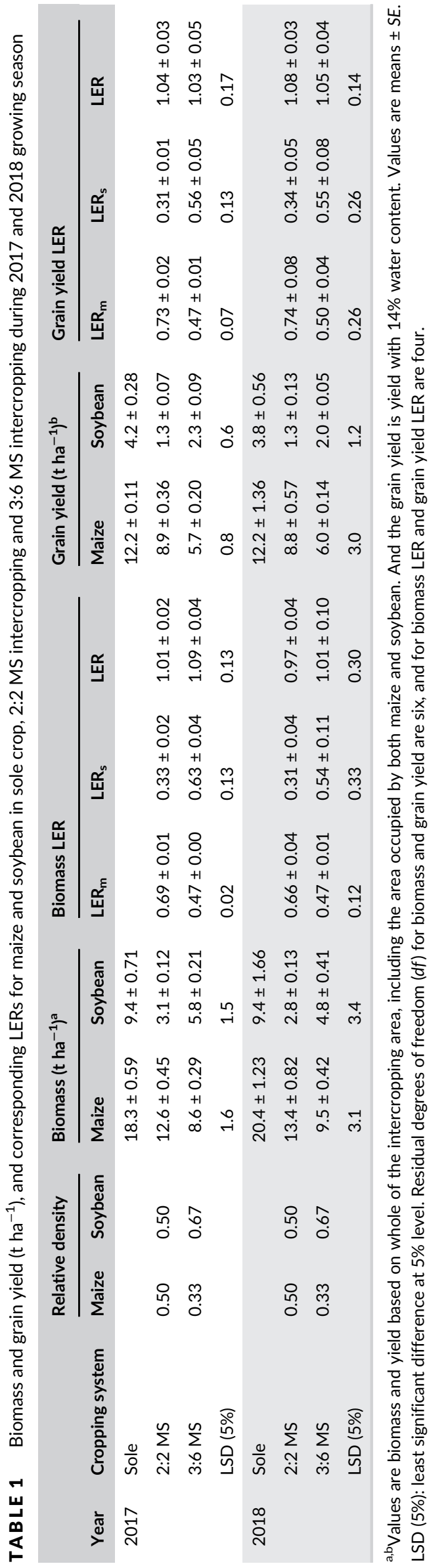

( $R$ Core Team, 2015) to assess the effects of intercropping and strip width on yield, yield components and plant traits in each year at the $5 \%(p=.05)$ level. There was intercropping effect when either 2:2 MS or 3:6 MS were different to the sole crop. Strip width effect existed when there was difference between 2:2 MS and 3:6 MS. In these two cases, differences between rows were not considered. To quantify the border row effect, data from border rows of intercrops were compared with data from inner rows of intercrops and sole crops. The differences between rows for each treatment in leaf area per plant, leaf area per rank and final soybean internode length per rank were analysed by one-way ANOVA. Linear regression to obtain phyllochron was made using linear mixed-effects model (Ime) in the "nlme" package of $\mathrm{R}$ with plot and plant (nested in plot) as random effects. The "ggplot2" package of R programming language (Wickham, 2009) was used to produce figures. Values in the Figures and Tables are means $\pm S E s$.

\section{3 | RESULTS}

\section{1 | Maize and soybean biomass, yield and yield components}

The wide strip treatment (3:6 MS with relative densities 0.33:0.67) had significantly lower maize biomass and yield but significantly higher soybean biomass and yield than the narrow strip treatment (2:2 MS with relative densities 0.50:0.50) in both 2017 and 2018 (Table 1). Biomass LER ranged from $0.97 \pm 0.04$ to $1.09 \pm 0.04$ and yield LER ranged from $1.03 \pm 0.05$ to $1.08 \pm 0.03$ in different intercropping configurations in the two years, with significant overyielding for biomass in the 3:6 system in 2017 and for yield in the 2:2 system in 2018 (Table 1). Overall, the land use advantage of intercropping was small (i.e., smaller than approximately $10 \%$ ).

Maize grain number per plant, yield and biomass per plant were higher in intercrops than in sole maize in 2017, but not in 2018 (Table 2). Intercropping significantly increased the harvest index of maize in 2:2 MS in 2017, but not in the 3:6 system, and not in either system in 2018. In the wide strip treatment (3:6 MS), border row effects were positive for maize grain number per plant, biomass per meter row and grain yield per meter row in both years (Figures 2 and 3). There were no differences in measured traits between the two rows of maize in the narrow strip intercrop (2:2 MS), which were both border rows.

Soybean had lower grain number and yield per plant in narrow strip (2:2 MS) intercropping than in the sole crop in 2017, but there was no difference between the intercropped and sole soybean in yield per plant in 2018 (Table 2). The greater width of the soybean strip in the 3:6 MS system did not result in a significant improvement in yield and biomass per plant or yield components (grain number per plant, 100 -grain weight and harvest index) compared with soybean in the narrow strip intercrop (2:2 MS) or the sole soybean crop in either of the two years. Border row effects, especially for the south row next to maize (S6) (i.e., the row most heavily shaded by maize), were 


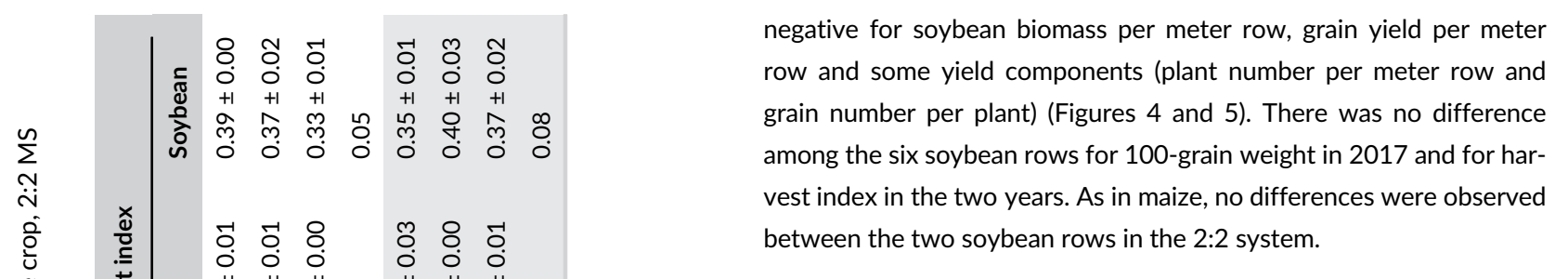

\section{2 | Aggressivity}

Relative performance per plant was substantially greater than one for maize (1.32-1.40 for biomass and 1.41-1.50 for yield) while it was considerably smaller than one for soybean (0.61-0.94 for biomass and 0.62-0.84 for yield) (Table 3). Maize was, therefore, aggressive to soybean, with $A_{m s}$ varying from 0.46 to 0.72 for biomass and from 0.56 to 0.84 for yield (Table 3 ). Reducing the relative density of maize from 0.5 in 2:2 MS to 0.33 in 3:6 MS significantly reduced the aggressivity of maize to soybean for both biomass and yield in 2017 but not in 2018 .

\section{3 | Developmental and architectural responses of maize and soybean to intercropping}

\subsection{1 | Leaf appearance}

The phyllochron, the thermal time requirement for appearance of successive leaves for maize from rank 7 onwards and soybean on the main stem, was different in the two years (Figure 6). Sole maize phyllochron was $52 \pm 1.2^{\circ} \mathrm{Cd}$ in 2017 and $49 \pm 2.3^{\circ} \mathrm{Cd}$ in 2018 , while sole soybean phyllochron was $39 \pm 0.5^{\circ} \mathrm{Cd}$ in 2017 and $44 \pm 0.8^{\circ} \mathrm{Cd}$ in 2018 . In 2017, intercropping significantly increased phyllochron of soybean, while phyllochron of maize in 2:2 MS was reduced. Intercropping did not affect leaf appearance, both for maize and soybean, in 2018.

\subsection{2 | Leaf area}

Maize leaf area per plant was similar before $900^{\circ} \mathrm{Cd}$, but was higher in 2:2 MS intercropping and in the border rows in 3:6 MS intercropping than in the sole crop beyond $900^{\circ} \mathrm{Cd}$ in both years (Figure 7). Leaf area per plant of maize was smaller in 3:6 MS intercropping than in 2:2 MS and plants in border rows of 3:6 produced more leaf area than plants in the inner row beyond $900^{\circ} \mathrm{Cd}$. Narrow strip intercropping (2:2 MS) significantly reduced soybean leaf area per plant from 600 to $1200^{\circ} \mathrm{Cd}$ (Figure 8). After $1200^{\circ} \mathrm{Cd}$ in 2017 , soybean leaf area per plant was higher in intercropping than in sole cropping. Soybean in the border rows of the wide strip system (3:6 MS) had the smallest leaf area per plant before $1200^{\circ} \mathrm{Cd}$. Maize plants in the narrow strip system (2:2 MS) and in the border rows in the wide strip system (3:6 MS) had greater leaf area per plant than plants in the inner row of 3:6 and the sole crop. Soybean leaf area growth was lower in intercrops than in the sole crop, and within 3:6 MS also lower in border rows than in inner rows. 
Intercropping mostly did not affect maize leaf area, but reduced soybean leaf area in some ranks, especially in plants in the border row of the wide strip system. Intercropping did not affect the final area of individual maize leaves in 2:2 MS intercropping, but the final area of several middle leaves of maize were slightly larger in the border rows (M1 and M3) of 3:6 MS intercropping than in the inner row (M2) (Figure 9). The final area of most soybean leaves was smaller in 2:2 MS intercropping than in the sole crop in both years, and for most ranks there were no significant differences in 3:6 MS intercropping due to large variation between plants (Figure 10).

\subsection{3 | Soybean internode length}

Soybean internode length was greater in 2:2 MS intercropping (narrow strips) than in the sole crop, especially from the 15th phytomer in 2017 and from the 14th phytomer in 2018 (Figure 11). Soybean internode length (at upper phytomers in 2017 and middle phytomers in 2018) was also greater in wide strip intercropping (3:6 MS) than in sole soybean. In border rows, soybean internode length was increased in intermediate phytomer ranks (phytomer rank from 7th to 11th), but decreased in the upper phytomer ranks, 16th to 18th. Plant height of soybean in intercropping was $93.7-109 \mathrm{~cm}$, substantially greater than the sole crop height $(85.7-90.4 \mathrm{~cm})$ (Table 4). Plant height was 8.0-8.5\% lower in wide soybean strips (3:6 MS) than in narrow strips (2:2 MS), indicating the presence of a strong shading effect in narrow strip intercropping. Intercrop maize was not different in height to sole maize, except for maize in 3:6 MS in 2017 (Table 4).

\subsection{4 | Ear/pod position, stem diameter and specific leaf area (SLA)}

Ear position of maize was lower in intercropping (2:2 MS and 3:6 MS) than in the sole crop in 2018 and also in 3:6 MS in 2017, but there was no significant difference in 2:2 MS in 2017 (Table 4). Intercropping had no effect on soybean pod position in both years. The stem diameter of intercropped maize was 1.02-1.06 times that in sole maize, but there was no significant difference. However, stem diameter was up to $30 \%$ smaller in intercropped soybean than in sole soybean in 2018. The SLA of maize was not different between intercrop and sole crop. In 2017, the SLA was higher in intercropping than in
FIGURE 2 Maize plant number per meter row ( $a$ and $b)$, grain number per plant (c and d) and 100-grain weight (e and f) in 2017 and 2018. On the horizontal axis, number M1-M3 denotes the number of rows from south to north. Data for sole maize are indicated in row 1 and data for maize in 2:2 MS are indicated in row 1 and row 3 . Values are means $\pm S E(n=3)$

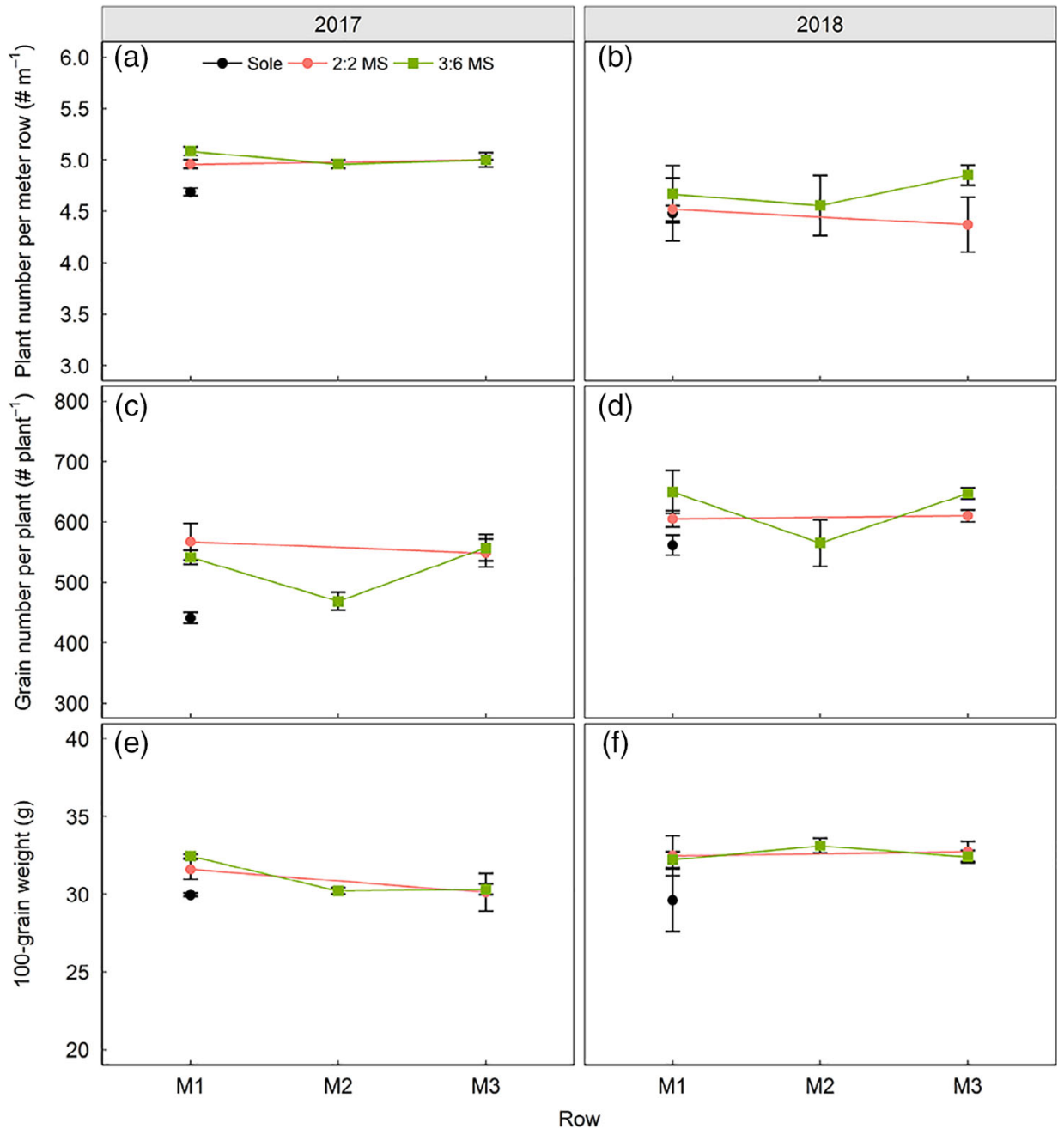


sole soybean: $27 \%$ higher in narrow strip intercropping (2:2 MS) and $17 \%$ higher in wide strip intercropping (3:6 MS). However, in 2018, no significant differences were found. Increasing strip width in intercropping (3:6 MS vs. 2:2 MS) did not affect plant architectural characteristics for both species, such as ear/pod position, stem diameter and SLA, except for soybean SLA in 2017.

\section{DISCUSSION}

This study aimed at quantifying the land use advantage of maize/soybean simultaneous intercropping, and relates this to border row effects and associated phenotypic plasticity effects. Maize in intercrops, especially in border rows had larger leaf area per plant and greater yields than in inner rows and in sole crop, indicating that maize plants in the border row captured more resources due to less intraspecific competition (Figures 3 and 7). Furthermore, maize plants in the border rows in the 3:6 system had greater yield per plant than those in the 2:2 system, indicating that maize plants benefited from wider soybean strips and a lower proportion of maize in the system. Soybean in intercrop border rows had reduced leaf area per plant, and overall thinner leaves and longer internodes due to strong competition with maize, resulting in less yield than inner row plants and sole soybean plants (Figure 5). The architectural responses of soybean to competition with maize fitted the shade avoidance syndrome (Pierik \& De Wit, 2014).

\section{1 | Land use advantage}

There was only a slight land use advantage in the simultaneous maize/ soybean intercropping system that we studied. This is a marked difference with results in maize/soybean relay intercropping (Yang et al., 2015, 2017) and other relay intercropping systems, which usually show considerable overyielding (Yu, Stomph, Makowski, Zhang, \& van der Werf, 2016). Recovery growth of the late harvested crop after harvest of the early sown species is an important component of overyielding ( $\mathrm{Li}$ et al., 2001). This recovery growth is due to the greater resource availability per plant of the remaining species and less interspecific interaction when the first has been harvested. This is, for instance, the case for maize in wheat/maize relay intercropping in Gansu province, China, and soybean in maize/soybean relay

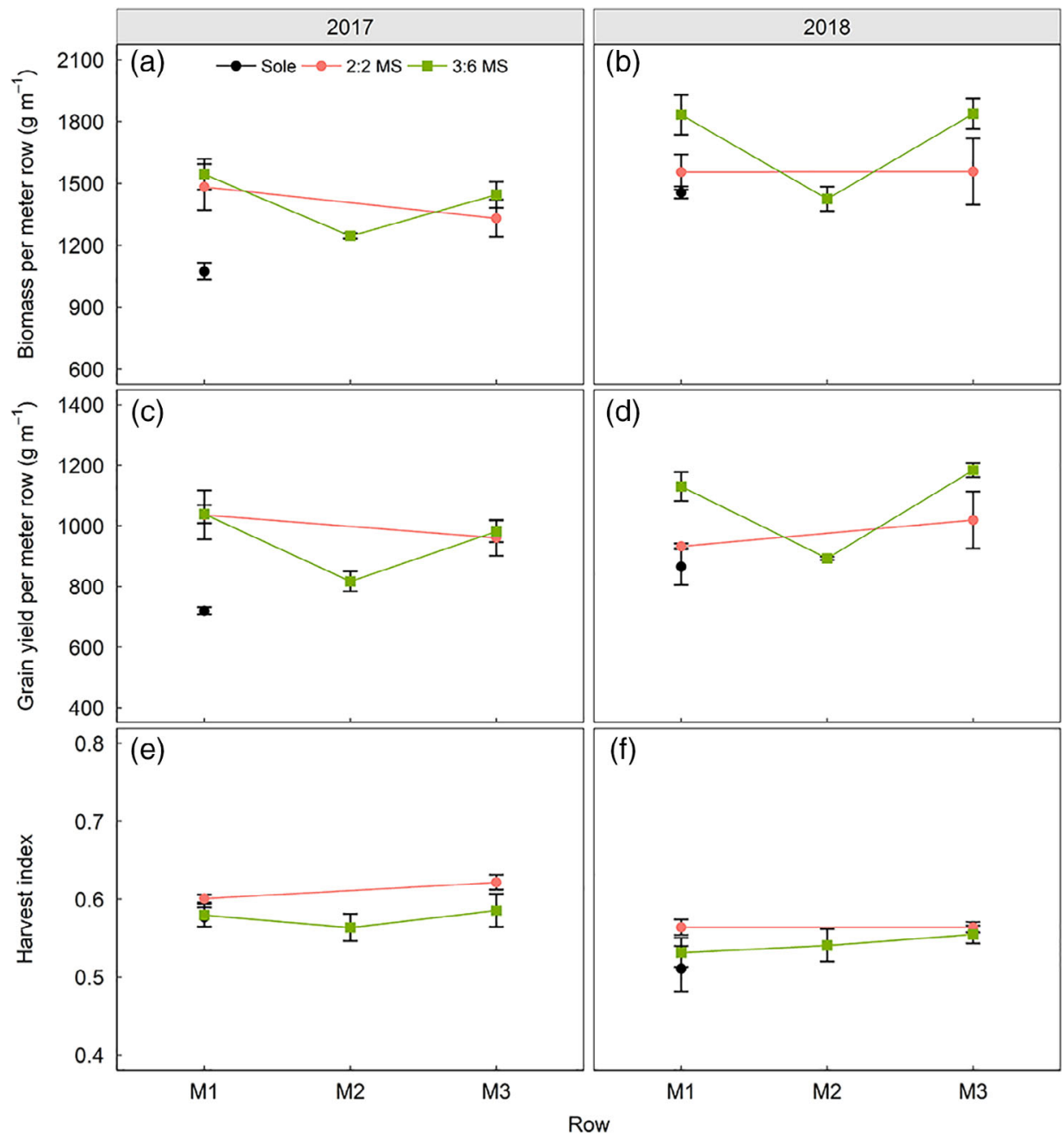

FIGURE 3 Maize biomass per meter row ( $a$ and $b$ ), grain yield per meter row ( $c$ and $d$ ) and harvest index (e and f) in 2017 and 2018. Grain yield is yield with $14 \%$ water content. On the horizontal axis, number M1-M3 denotes the number of rows from south to north. Data for sole maize are indicated in row 1 and data for maize in 2:2 MS are indicated in row 1 and row 3 . The grain yield per meter row is calculated by yield components as follows: grain yield per meter row $=$ plant number per meter row $x$ grain number per plant $x$ grain weight. Values are means $\pm S E(n=3)$ 
FIGURE 4 Soybean plant number per meter row ( $a$ and $b$ ), grain number per plant (c and d) and 100-grain weight (e and f) in 2017 and 2018. On the horizontal axis, number S1-S6 denotes the number of rows from north to south. Data for sole soybean are indicated in row 1 and data for maize in 2:2 MS are indicated in row 1 and row 6 . Values are means \pm $S E(n=3)$

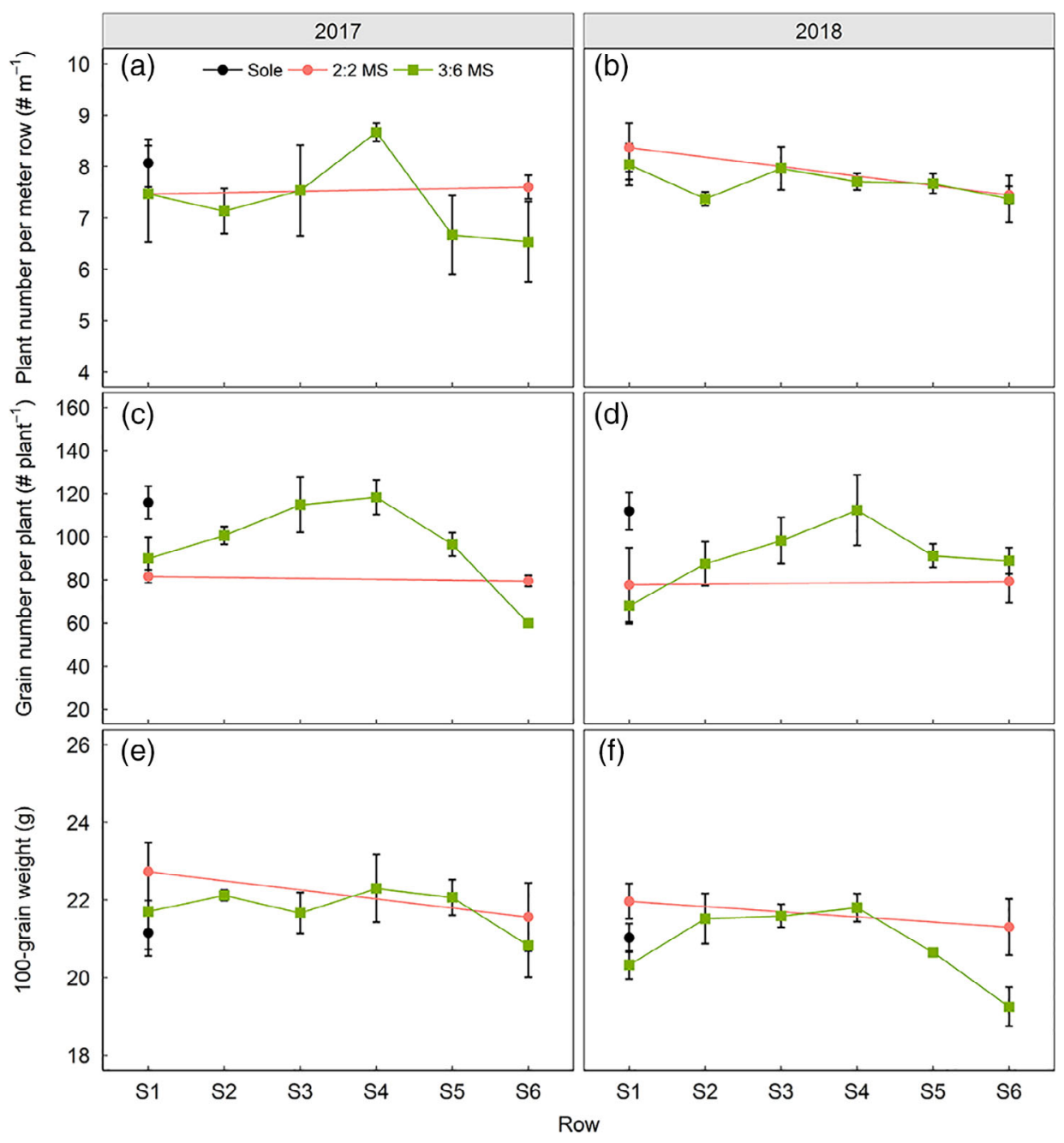

intercropping in southwest China (e.g., Sichuan province) (Li et al., 2001; Yang et al., 2017). Likewise, border plants in early sown crops in relay intercropping have advantageous growing conditions during early growth because of the absence of a strong competitor in the neighbouring strip, resulting in major overyielding in the border rows of the early sown species (Gou et al., 2016; Zhu et al., 2015, 2016). However, maize and soybean were sown and harvested at the same time in our experiments, leading to serious interspecific competition. Temporal niche differentiation and competition recovery period for the late harvested species did not exist, and thus niches for extra resource capture, which do occur in relayintercropping (Zhu et al., 2015, 2016), were not demonstrated in our study. Plastic responses observed in soybean in our study are, for the most part, associated with the aggressivity of maize. Therefore, any advantages from intercropping in the simultaneous maize/soybean would for the most part or even exclusively result from spatial complementarity in the acquisition of resources.

Maize plants were higher than soybean throughout the entire growing season (Figure S1), allowing it to capture more light, leading to a higher maize plant performance in intercrops as compared to sole maize (Gao et al., 2010). Even though soybean in the shade of maize may become more efficient in light use because of a higher fraction of diffuse light reaching its canopy (Liu et al., 2017), the low soybean yields in intercropping in our study show that this did not compensate for the reduced amount of light reaching the soybean plants. As a result, the high maize yield in intercropping was offset by a low soybean yield.

Cereal/legume intercropping systems are known to be advantageous under low input conditions due to complementarity for $\mathrm{N}$ acquisition (from soil by the cereal and from air by the legume) (Bedoussac et al., 2015; Hauggaard-Nielsen, Ambus, \& Jensen, 2001). However, current agriculture in China is high input and high output ( $F$. Zhang et al., 2012). In our study, we gave $240 \mathrm{~kg} \mathrm{ha}^{-1} \mathrm{~N}$ input to maize and $80 \mathrm{~kg} \mathrm{ha}^{-1} \mathrm{~N}$ to soybean. Accordingly, we expected a minor contribution from complementarity for $\mathrm{N}$ acquisition under the growing conditions of the study, if any. The results of the study confirm this expectation, and corroborate the literature that cereal/legume intercropping systems are advantageous at low $\mathrm{N}$ input, but not necessarily at high N input (Ahmed \& Rao, 1982; Yu et al., 2016).

Effects of complementarity for water uptake on intercrop performance cannot be ruled out in our study. The crops in this study were rain-fed and the total precipitation during the growing period was $478 \mathrm{~mm}$ in 2017 and $465 \mathrm{~mm}$ in 2018 (Table S1), which was not 


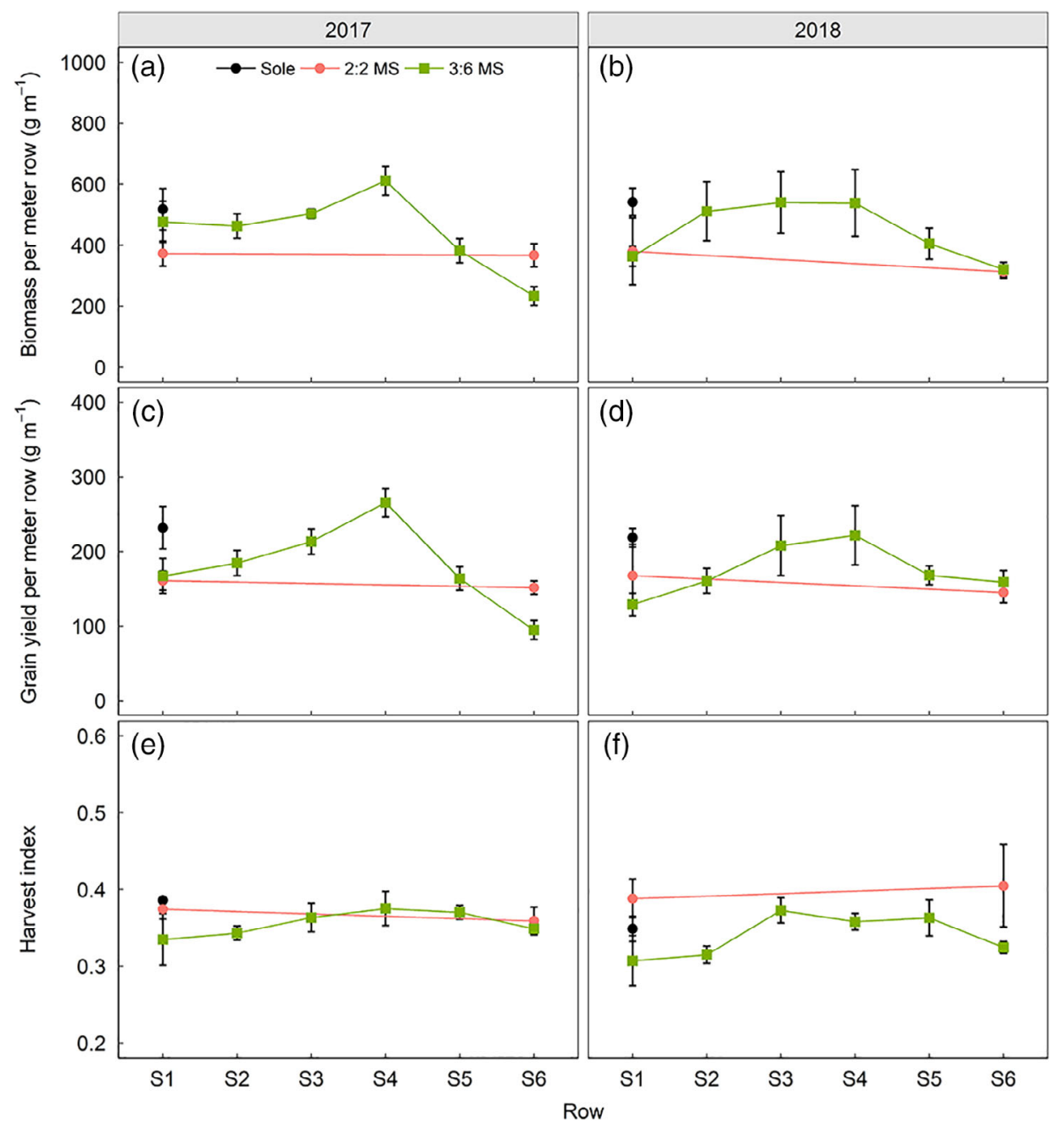

FIGURE 5 Soybean biomass per meter row ( $a$ and $b$ ), grain yield per metre row (c and d) and harvest index (e and f) in 2017 and 2018. Grain yield is yield with $14 \%$ water content. On the horizontal axis, number S1-S6 denotes the number of rows from north to south. Data for sole soybean are indicated in row 1 and data for maize in 2:2 MS are indicated in row 1 and row 6 . The grain yield per meter row is calculated by yield components as follows: grain yield per meter row $=$ plant number per meter row $x$ grain number per plant $\times$ grain weight. Values are means $\pm S E(n=3)$

TAB LE 3 Aggressivity of maize and soybean in 2:2 MS intercropping and 3:6 MS intercropping during 2017 and 2018 growing season

\begin{tabular}{|c|c|c|c|c|c|c|c|}
\hline Year & Treatment & \multicolumn{3}{|l|}{ Biomass } & \multicolumn{3}{|l|}{ Grain yield } \\
\hline \multirow[t]{3}{*}{2017} & $2: 2 \mathrm{MS}$ & $1.37 \pm 0.01$ & $0.65 \pm 0.04$ & $0.72 \pm 0.05$ & $1.46 \pm 0.05$ & $0.62 \pm 0.01$ & $0.84 \pm 0.03$ \\
\hline & $3: 6 \mathrm{MS}$ & $1.40 \pm 0.01$ & $0.94 \pm 0.06$ & $0.46 \pm 0.07$ & $1.41 \pm 0.04$ & $0.84 \pm 0.07$ & $0.56 \pm 0.05$ \\
\hline & LSD (5\%) & 0.05 & 0.21 & 0.22 & 0.16 & 0.19 & 0.17 \\
\hline \multirow[t]{2}{*}{2018} & $2: 2 \mathrm{MS}$ & $1.32 \pm 0.08$ & $0.61 \pm 0.07$ & $0.70 \pm 0.14$ & $1.47 \pm 0.17$ & $0.68 \pm 0.10$ & $0.79 \pm 0.27$ \\
\hline & LSD (5\%) & 0.25 & 0.51 & 0.67 & 0.59 & 0.44 & 1.02 \\
\hline
\end{tabular}

$A_{m}$ and $A_{s}$ represent the relative size of individual plants of maize and soybean in the intercrop compared to the sole crop. $A_{m s}$ represents the aggressivity of maize when compared with soybean. Grain yield is yield with $14 \%$ water content. Values are means \pm SE. LSD (5\%): least significant difference at $5 \%$ level. Residual degrees of freedom (df) for all variables are four.

evenly distributed through the growing season. Interspecific interaction between water uptake by the root systems of the two species will be important to use this limited water. Intercropping increases the total root length density for both maize and soybean (Ren, Wang, Zhang, Palta, \& Chen, 2017), indicating that interspecific interaction could enhance crop root proliferation and the soil volume used to explore water resources in the soil profile and consequently improve the yield.

\section{2 | Border row effects on maize reproductive growth}

The positive effect of intercropping on maize and the negative effect on soybean were primarily visible in the border rows, corroborating earlier work (Lesoing \& Francis, 1999), where maize and soybean were grown in strip intercropping in eastern Nebraska, USA. It showed that maize in border row had significantly increased grain number and 
FIGURE 6 Leaf appearance as a function of leaf number with maize ( $a$ and $b$ ) and soybean ( $c$ and $d$ ) in different configurations during 2017 and 2018 growing season. Values are means $\pm S E(n=6)$
FIGURE 7 Leaf area per plant of maize in 2:2 MS intercropping ( $a$ and $b$ ) and 3:6 MS intercropping (c and d) during 2017 and 2018 growing season. To quantify the differences in growth and development of the plants between rows in an intercrop strip, we distinguished the maize border rows (M1 and M2 in 2:2 MS intercropping; $M 1$ and $M 3$ in 3:6 MS intercropping) from inner row (M2 in 3:6 MS intercropping). Bars are the LSD (least significant difference) at $5 \%$ level. Residual degrees of freedom ( $d f$ ) was four for 2:2 MS and six for 3:6 MS
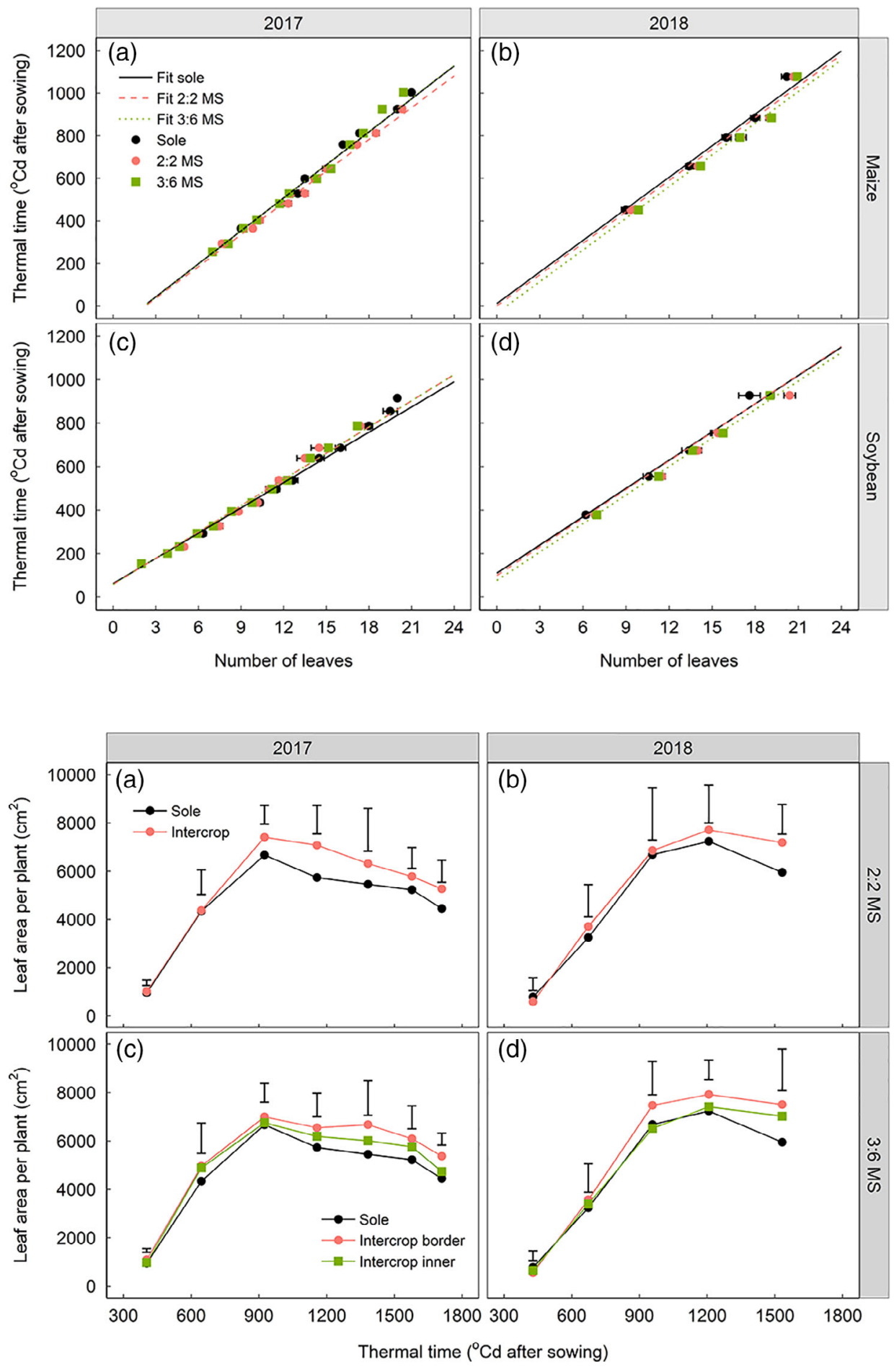

grain weight, whereas soybean had reduced grain number, which contributed to the yield formation. In our study, increased maize grain number per plant and reduced soybean grain number per plant in intercropping were also found for plants in border rows (Figures 2 and 4). These differences in grain number associated with yield differences between the intercrop and sole crop and are likely to be due to the effects of intercropping on the light environment during flowering (Andrade et al., 1999; Borrás \& Westgate, 2006; Gambín, Borrás, \& Otegui, 2006; Ghanbari, Dahmardeh, Siahsar, \& Ramroudi, 2010). In this period, plants are adjusting their flower numbers to the rate of plant growth (Borrás \& Westgate, 2006). Therefore, the taller maize next to the shorter soybean could capture more resources during the reproductive and grain-filling period, boosting yield, whereas soybean captured less resources, resulting in less yield.

\section{3 | Plant development and architecture}

In wheat/maize relay strip intercropping, maize is initially shaded by the earlier sown wheat, reducing sheath elongation and lowering leaf 

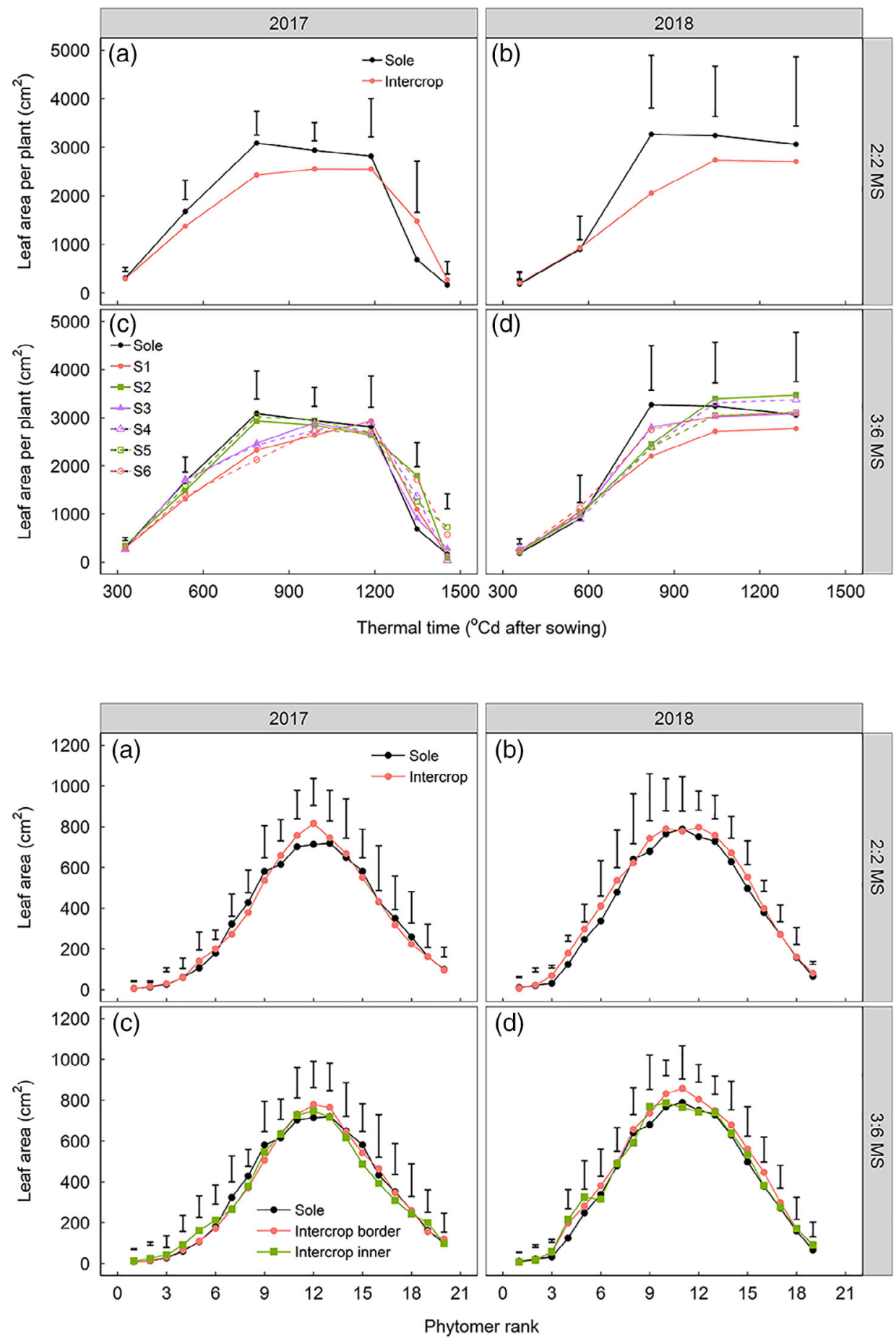

FIGURE 8 Leaf area per plant of soybean in 2:2 MS intercropping (a and b) and 3:6 MS intercropping (c and d) during 2017 and 2018 growing season. S1-S6 are row positions of the soybean strip in 3:6 MS intercropping (see Figure 1). Bars are the LSD (least significant difference) at $5 \%$ level. Residual degrees of freedom (df) was four for 2:2 MS and 14 for 3:6 MS
FIGURE 9 Final leaf area of maize in 2:2 MS intercropping ( $a$ and $b$ ) and 3:6 MS intercropping (c and d) related to phytomer rank during 2017 and 2018 growing season. To quantify the differences in growth and development of the plants between rows in an intercrop strip, we distinguished the maize border rows (M1 and M2 in 2:2 MS intercropping; $\mathrm{M} 1$ and $\mathrm{M} 3$ in 3:6 MS intercropping) from inner row (M2 in 3:6 MS intercropping). Bars are the LSD (least significant difference) at $5 \%$ level. Residual degrees of freedom ( $d f$ ) was four for 2:2 MS and six for 3:6 MS appearance rate of maize (Zhu, Vos, van der Werf, van der Putten, \& Evers, 2014). In maize/soybean simultaneous strip intercropping, shading of the soybean by maize leads to delayed soybean leaf appearance after the 5th phytomer (Liu et al., 2017). In the simultaneous maize/soybean system of our study, the seedlings of soybean in 2017 also experienced shading, resulting in delayed leaf appearance. This shading effect was influenced by weather conditions. For instance, maize plants were taller in 2017 than in 2018 (228-237 cm in 2017 vs. $207-212 \mathrm{~cm}$ in 2018 , Table 4), due to better moisture conditions after sowing. As a result of the taller maize in 2017, shading effects on soybean were stronger in this year than in 2018 (Raza et al., 2019).

Intercropped soybean displayed typical shade avoidance responses, especially in the narrow strips, for example, higher SLA and longer internodes (Pierik \& De Wit, 2014). The responses were stronger when soybean plants were closer to the maize in 3:6 MS, similar to earlier findings in relay intercropping of maize and soybean (Liu et al., 2017). The investment in height growth at the expense of leaf area growth (Figures 8, 10 and 11) is meant to result in adequate light capture once the competition is avoided. However, the size difference 
FIGURE 10 Final leaf area of soybean in 2:2 MS intercropping ( $a$ and $b$ ) and 3:6 MS intercropping (c and d) related to phytomer rank during 2017 and 2018 growing season. S1-S6 are row positions of the soybean strip in 3:6 MS intercropping (see Figure 1). Bars are the LSD (least significant difference) at $5 \%$ level. Residual degrees of freedom $(d f)$ was four for 2:2 MS and 14 for 3:6 MS

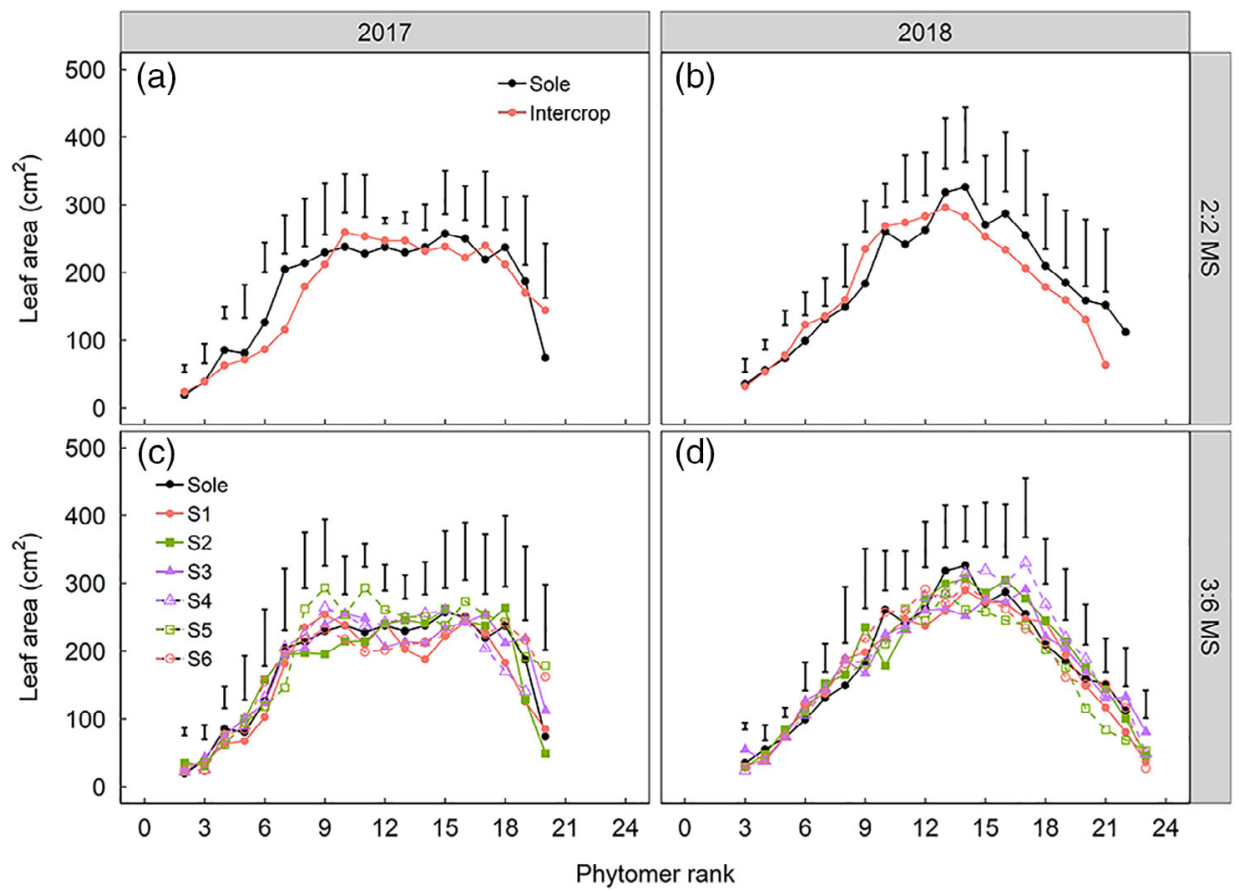

FIGURE 11 Final internode length of soybean in 2:2 MS intercropping ( $a$ and $b$ ) and 3:6 MS intercropping (c and d) during 2017 and 2018 growing season. S1-S6 are row positions of the soybean strip in 3:6 MS intercropping (see Figure 1). Bars are the LSD (least significant difference) at $5 \%$ level. Residual degrees of freedom ( $d f$ ) was four for 2:2 MS and 14 for 3:6 MS

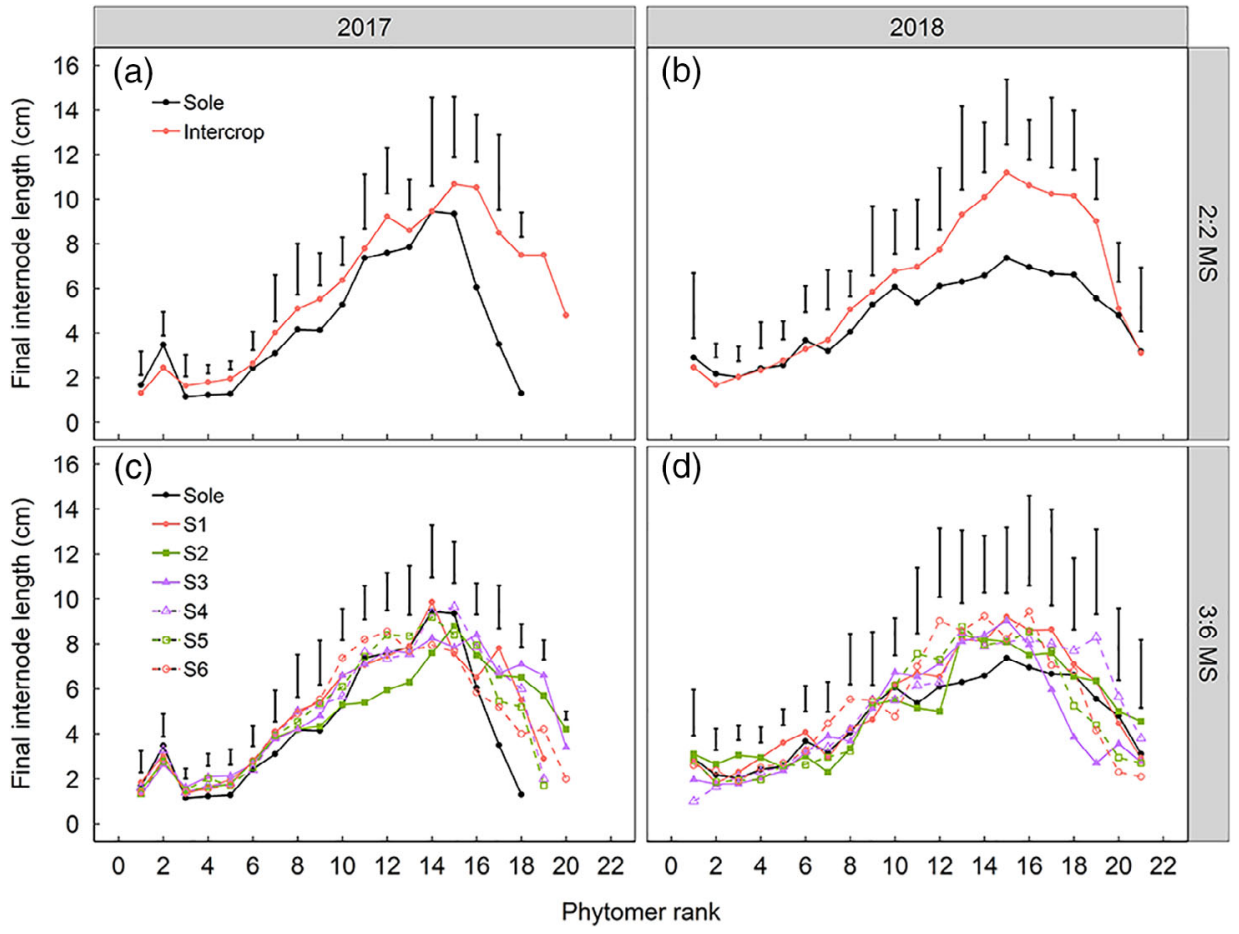

of soybean with maize was such that this improvement in light capture was likely never reached, leading to suboptimal performance of soybean in the intercrops (Figure 5). This shows that when interspecific competition is fierce, it cannot always be overcome by adopting a competition-avoiding growth strategy. This implies that any efforts for crop improvement in intercrops should be done, taking into account the extent of phenotypic plasticity of the component species: if the tipping point where plasticity starts to pay off is never reached because differences in, for instance, stature between species are too large, performance of the whole system may suffer. In such an instance, it may be beneficial for intercropping to select plants that are less plastic in their growth habit in response to shading (Gong et al., 2015; Wu et al., 2017). If plastic growth responses do result in a better competition for light by the subordinate species, the performance of this species will tend to improve, but this could go at the expense of the dominant species. Selection of suitable genotypes for intercropping should take into account whether or not shade avoidance responses are likely to be beneficial or not, and both the 
TA B LE 4 Plant height $(\mathrm{cm})$, ear/pod position $(\mathrm{cm})$, stem diameter $(\mathrm{mm})$ and specific leaf area $\left(\mathrm{cm}^{2} \mathrm{~g}^{-1}\right)$ of maize and soybean in sole crop, 2:2 MS intercropping and 3:6 MS intercropping during 2017 and 2018 growing season

\begin{tabular}{|c|c|c|c|c|c|c|c|c|c|}
\hline Year & Treatment & \multicolumn{2}{|c|}{ Plant height $(\mathrm{cm})$} & \multicolumn{2}{|c|}{ Ear/Pod position $(\mathrm{cm})^{\mathrm{a}}$} & \multicolumn{2}{|c|}{ Stem diameter (mm) } & \multicolumn{2}{|c|}{ Specific leaf area $\left(\mathrm{cm}^{2} \mathrm{~g}^{-1}\right)$} \\
\hline \multirow[t]{3}{*}{2017} & Sole & $238.6 \pm 2.3$ & $90.4 \pm 1.8$ & $109.4 \pm 1.5$ & $13.9 \pm 1.0$ & $19.65 \pm 0.62$ & $8.85 \pm 0.52$ & $174.2 \pm 3.2$ & $196.0 \pm 5.7$ \\
\hline & 3:6 MS & $228.2 \pm 1.8$ & $101.0 \pm 2.9$ & $101.9 \pm 2.0$ & $15.7 \pm 1.2$ & $20.03 \pm 0.55$ & $8.83 \pm 0.04$ & $173.9 \pm 10.9$ & $228.4 \pm 2.0$ \\
\hline & LSD (5\%) & 8.0 & 16.0 & 6.9 & 5.8 & 1.79 & 1.56 & 26.5 & 13.7 \\
\hline \multirow{3}{*}{2018} & $2: 2 \mathrm{MS}$ & $212.2 \pm 8.2$ & $102.4 \pm 4.6$ & $103.0 \pm 2.3$ & $21.2 \pm 1.0$ & $22.57 \pm 0.39$ & $8.35 \pm 0.40$ & $162.0 \pm 18.8$ & $297.6 \pm 26.8$ \\
\hline & $3: 6 \mathrm{MS}$ & $207.5 \pm 2.9$ & $93.7 \pm 6.1$ & $104.4 \pm 1.0$ & $20.0 \pm 1.2$ & $23.24 \pm 0.96$ & $9.63 \pm 0.75$ & $160.8 \pm 1.9$ & $266.9 \pm 12.0$ \\
\hline & LSD (5\%) & 21.8 & 20.1 & 5.0 & 3.4 & 2.15 & 2.41 & 40.3 & 80.2 \\
\hline
\end{tabular}

${ }^{a}$ Ear position of maize is the height of main ear phytomer and the pod position is the height of the rank that had seed-bearing pods. Values are means $\pm S E$. LSD (5\%): least significant difference at $5 \%$ level. Residual degrees of freedom (df) for all variables are six.

performance of the subordinate and dominant species may need to be considered.

How the combined effects play out at the crop level can be addressed using plant modelling in which plant architecture, growth and plastic responses in intercrops are considered (Evers et al., 2019). For practice, it may be beneficial to either grow maize/soybean intercrops with wide enough strips for soybean to get enough light (Liu et al., 2018), or use shadetolerant varieties that do not exhibit strong shade avoidance responses that are bound to be futile because of the large difference in plant height between maize and soybean. Another opportunity for optimising the performance of soybean in this system may be to use short straw maize varieties or manipulate the seed (e.g., sowing depth or pre-treatments) such that germination of soybean is advanced in comparison to maize.

\section{5 | CONCLUSIONS}

In this study we quantified the contribution of plasticity in relation to strip width and row position in a simultaneous maize/soybean intercrop to productivity, both at species and at the intercrop system level. We showed that a simultaneously sown and harvested maize/soybean intercrop performed only slightly better than the respective sole crops because relevant mechanisms for temporal or spatial complementarity were lacking. Maize performed better in the intercrop than in the sole crop, at the expense of soybean. Although the latter displayed typical shadeavoidance responses to cope with maize competition, these responses were not sufficient to lift the soybean leaves into the full light, leading to suboptimal soybean performance. This shows the relevance of considering, appropriately, plastic genotypes and suitable spatial-temporal species configurations when designing intercropping systems.

These findings give important insight in the role of architectural trait plasticity in relation to intercropping. In systems that by design allow additional resource capture (e.g., relay intercropping), architectural plasticity contributes to the realisation of this extra resource capture. On the other hand, in systems in which complementarity for above ground resource capture is difficult to achieve (as in our study system), architectural trait responses do occur, but they do not contribute to overyielding, although they probably do contribute to mitigating the loss for the shaded species.

\section{ACKNOWLEDGEMENTS}

This work was jointly supported by the National Key Research and Development Program of China (2016YFD0300202; 31000671), Science and Technology projects from Yunnan (2017YN07) and Inner Mongolia. We acknowledge Ziwen Xie and Wenfeng Wu for valuable help and contributions to the experiment, the financial support of the China Scholarship Council (CSC201706350202).

\section{CONFLICT OF INTEREST}

The authors declare that there is no conflict of interest.

\section{ORCID}

Shuangwei Li (D) https://orcid.org/0000-0002-2694-550X

\section{REFERENCES}

Ahmed, S., \& Rao, M. R. (1982). Performance of maize-soybean intercrop combination in the tropics: Results of a multi-location study. Field Crops Research, 5, 147-161.

Ahmed, S., Raza, M., Zhou, T., Hussain, S., Khalid, M., Feng, L., ... Yang, W. (2018). Responses of soybean dry matter production, phosphorus accumulation, and seed yield to sowing time under relay intercropping with maize. Agronomy, 8(12), 282.

Andrade, F. H., Vega, C., Uhart, S., Cirilo, A., Cantarero, M., \& Valentinuz, O. (1999). Kernel number determination in maize. Crop Science, 39(2), 453-459.

Bedoussac, L., Journet, E. P., Hauggaard-Nielsen, H., Naudin, C., CorreHellou, G., Jensen, E. S., ... Justes, E. (2015). Ecological principles underlying the increase of productivity achieved by cereal-grain legume intercrops in organic farming. A review. Agronomy for Sustainable Development, 35(3), 911-935.

Borrás, L., \& Westgate, M. E. (2006). Predicting maize kernel sink capacity early in development. Field Crops Research, 95(2-3), 223-233. 
Boudreau, M. A. (2013). Diseases in intercropping systems. Annual Review of Phytopathology, 51, 499-519.

Brooker, R. W., Bennett, A. E., Cong, W., Daniell, T. J., George, T. S., Hallett, P. D., ... White, P. J. (2015). Improving intercropping: A synthesis of research in agronomy, plant physiology and ecology. New Phytologist, 206(1), 107-117.

Chen, Z., Cui, H., Wu, P., Zhao, Y., \& Sun, Y. (2010). Study on the optimal intercropping width to control wind erosion in North China. Soil and Tillage Research, 110(2), 230-235.

Cong, W., Hoffland, E., Li, L., Six, J., Sun, J., Bao, X., ... van der Werf, W. (2015). Intercropping enhances soil carbon and nitrogen. Global Change Biology, 21(4), 1715-1726.

Du, J., Han, T., Gai, J., Yong, T., Sun, X., Wang, X., ... Yang, W. (2018). Maize-soybean strip intercropping: Achieved a balance between high productivity and sustainability. Journal of Integrative Agriculture, 17(4), 747-754.

Echarte, L., Della Maggiora, A., Cerrudo, D., Gonzalez, V. H., Abbate, P., Cerrudo, A., ... Calviño, P. (2011). Yield response to plant density of maize and sunflower intercropped with soybean. Field Crops Research, 121(3), 423-429.

Evers, J. B., van der Werf, W., Stomph, T. J., Bastiaans, L., \& Anten, N. P. R. (2019). Understanding and optimizing species mixtures using functional-structural plant modelling. Journal of Experimental Botany, 70, 2381-2388.

Exner, D. N., Davidson, D. G., Ghaffarzadeh, M., \& Cruse, R. M. (1999). Yields and returns from strip intercropping on six lowa farms. American Journal of Alternative Agriculture, 14(2), 69-77.

Gambín, B. L., Borrás, L., \& Otegui, M. E. (2006). Source-sink relations and kernel weight differences in maize temperate hybrids. Field Crops Research, 95(2-3), 316-326.

Gao, Y., Duan, A., Qiu, X., Sun, J., Zhang, J., Liu, H., \& Wang, H. (2010). Distribution and use efficiency of photosynthetically active radiation in strip intercropping of maize and soybean. Agronomy Journal, 102(4), 1149-1157.

Ghaffarzadeh, M., Préchac, F. G., \& Cruse, R. M. (1994). Grain yield response of corn, soybean, and oat grown in a strip intercropping system. American Journal of Alternative Agriculture, 9(9), 171-177.

Ghanbari, A., Dahmardeh, M., Siahsar, B. A., \& Ramroudi, M. (2010). Effect of maize (Zea mays L.)-cowpea (Vigna unguiculata L.) intercropping on light distribution, soil temperature and soil moisture in arid environment. Journal of Food, Agriculture and Environment, 8(1), 102-108.

Gong, W. Z., Jiang, C. D., Wu, Y. S., Chen, H. H., Liu, W. Y., \& Yang, W. Y. (2015). Tolerance vs. avoidance: Two strategies of soybean (Glycine max) seedlings in response to shade in intercropping. Photosynthetica, 53(2), 259-268.

Gou, F., Van Ittersum, M. K., Couëdel, A., Zhang, Y., Wang, Y., van der Putten, P. E. L., ... van der Werf, W. (2018). Intercropping with wheat lowers nutrient uptake and biomass accumulation of maize, but increases photosynthetic rate of the ear leaf. AoB Plants, 10(1), ply010.

Gou, F., van Ittersum, M. K., Wang, G., van der Putten, P. E. L., \& van der Werf, W. (2016). Yield and yield components of wheat and maize in wheat-maize intercropping in the Netherlands. European Journal of Agronomy, 76, 17-27.

Grime, J. P. (1987). Dominant and subordinate components of plant communities: Implications for succession, stability and diversity. In A. H. Gray \& M. J. Crawley (Eds.), Colonization, succession and stability (pp. 413-428). Oxford, England: Blackwell.

Hauggaard-Nielsen, H., Ambus, P., \& Jensen, E. S. (2001). Temporal and spatial distribution of roots and competition for nitrogen in pea-barley intercrops - a field study employing ${ }^{32} \mathrm{P}$ technique. Plant and Soil, 236 (1), 63-74.

Lesoing, G. W., \& Francis, C. A. (1999). Strip intercropping effects on yield and yield components of corn, grain sorghum, and soybean. Agronomy Journal, 91(5), 807-813.
Li, L., Sun, J., Zhang, F., Li, X., Rengel, Z., \& Yang, S. (2001). Wheat/maize or wheat/soybean strip intercropping: II. Recovery or compensation of maize and soybean after wheat harvesting. Field Crops Research, 71(3), 173-181.

Li, L., Zhang, L., \& Zhang, F. (2013). Crop mixtures and the mechanisms of overyielding. In S. A. Levin (Eds), Encyclopedia of Biodiversity (Vol. 2, pp. 382-395). Waltham, Massachusetts: Academic Press.

Liang, K., Yang, T., Zhang, S., Zhang, J., Luo, M., Fu, L., \& Zhao, B. (2016). Effects of intercropping rice and water spinach on net yields and pest control: An experiment in southern China. International Journal of Agricultural Sustainability, 14(4), 448-465.

Liebman, M., \& Dyck, E. (1993). Crop rotation and intercropping strategies for weed management. Ecological Applications, 3(1), 92-122.

Liu, X., Rahman, T., Song, C., Su, B., Yang, F., Yong, T., ... Yang, W. (2017). Changes in light environment, morphology, growth and yield of soybean in maize-soybean intercropping systems. Field Crops Research, 200, 38-46.

Liu, X., Rahman, T., Song, C., Yang, F., Su, B., Cui, L., ... Yang, W. (2018). Relationships among light distribution, radiation use efficiency and land equivalent ratio in maize-soybean strip intercropping. Field Crops Research, 224, 91-101.

Lv, Y., Francis, C., Wu, P., Chen, X., \& Zhao, X. (2014). Maize-soybean intercropping interactions above and below ground. Crop Science, 54 (3), 914-922.

Major, D. J., Johnson, D. R., Tanner, J. W., \& Anderson, I. C. (1975). Effects of daylength and temperature on soybean development. Crop Science, 15(2), 174-179.

Mao, L., Zhang, L., Li, W., van der Werf, W., Sun, J., Spiertz, H., \& Long, L. (2012). Yield advantage and water saving in maize/pea intercrop. Field Crops Research, 138, 11-20.

McGilchrist, C. A. (1965). Analysis of competition experiments. Biometrics, 21, 975-985.

Morris, R. A., \& Garrity, D. P. (1993). Resource capture and utilization in intercropping: Water. Field Crops Research, 34(3-4), 303-317.

Ofori, F., \& Stern, W. R. (1987). Cereal-legume intercropping systems. Advances in Agronomy, 41, 41-90.

Pierik, R., \& De Wit, M. (2014). Shade avoidance: Phytochrome signalling and other aboveground neighbour detection cues. Journal of Experimental Botany, 65(11), 2815-2824.

R Core Team. (2015). R: A language and environment for statistical computing. Vienna, Austria: R Foundation for Statistical Computing. Retrieved from http://www.R-project.org/

Rao, M. R., \& Willey, R. W. (1980). Evaluation of yield stability in intercropping: Studies on sorghum-pigeonpea. Experimental Agriculture, 16 (2), 105-116.

Raza, M. A., Feng, L., Iqbal, N., Ahmed, M., Chen, Y., Khalid, M. H. B., ... Yang, W. (2019). Growth and development of soybean under changing light environments in relay intercropping system. PeerJ, 7, 7262.

Ren, Y., Wang, X., Zhang, S., Palta, J. A., \& Chen, Y. (2017). Influence of spatial arrangement in maize-soybean intercropping on root growth and water use efficiency. Plant and Soil, 415(1-2), 131-144.

Ritchie, J. T., \& NeSmith, D. S. (1991). Temperature and crop development. In J. Hanks \& J. T. Ritchie (Eds.), Modeling plant and soil systems, (modelingplantan) (Vol. 31, pp. 5-29). Madison, WI: American Society of Agronomy, Crop Science Society of America, Soil Science Society of America.

Saucke, H., \& Ackermann, K. (2006). Weed suppression in mixed cropped grain peas and false flax (Camelina sativa). Weed Research, 46(6), 453-461.

Vandermeer, J. (1989). The ecology of intercropping. Cambridge, England: Cambridge University Press.

Wang, Q., Sun, D., Hao, H., Zhao, X., Hao, W., \& Liu, Q. (2015). Photosynthetically active radiation determining yields for an intercrop of maize with cabbage. European Journal of Agronomy, 69, 32-40.

Wang, Z., Wu, P., Zhao, X., Gao, Y., \& Chen, X. (2015). Water use and crop coefficient of the wheat-maize strip intercropping system for an arid region in northwestern China. Agricultural Water Management, 161, 77-85. 
Wickham, H. (2009). ggplot2: Elegant graphics for data analysis. New York, NY: Springer.

Wu, Y., Yang, F., Gong, W., Ahmed, S., Fan, Y., Wu, X., ... Yang, W. (2017). Shade adaptive response and yield analysis of different soybean genotypes in relay intercropping systems. Journal of Integrative Agriculture, 16(6), 1331-1340.

Yang, F., Huang, S., Gao, R., Liu, W., Yong, T., Wang, X., ... Yang, W. (2014). Growth of soybean seedlings in relay strip intercropping systems in relation to light quantity and red:far-red ratio. Field Crops Research, 155, 245-253.

Yang, F., Liao, D., Wu, X., Gao, R., Fan, Y., Raza, M. A., ... Yang, W. (2017). Effect of aboveground and belowground interactions on the intercrop yields in maize-soybean relay intercropping systems. Field Crops Research, 203, 16-23.

Yang, F., Wang, X., Liao, D., Lu, F., Gao, R., Liu, W., ... Yang, W. (2015). Yield response to different planting geometries in maize-soybean relay strip intercropping systems. Agronomy Journal, 107(1), 296-304.

Yu, Y., Stomph, T. J., Makowski, D., \& van der Werf, W. (2015). Temporal niche differentiation increases the land equivalent ratio of annual intercrops: A meta-analysis. Field Crops Research, 184, 133-144.

Yu, Y., Stomph, T. J., Makowski, D., Zhang, L., \& van der Werf, W. (2016). A meta-analysis of relative crop yields in cereal/legume mixtures suggests options for management. Field Crops Research, 198, 269-279.

Zhang, F., Cui, Z., Chen, X., Ju, X., Shen, J., Chen, Q., ... Jiang, R. (2012). Integrated nutrient management for food security and environmental quality in China. Advances in Agronomy, 116, 1-40.

Zhang, F., \& Li, L. (2003). Using competitive and facilitative interactions in intercropping systems enhances crop productivity and nutrient-use efficiency. Plant and Soil, 248(1-2), 305-312.
Zhang, L., van der Werf, W., Bastiaans, L., Zhang, S., Li, B., \& Spiertz, J. H. J. (2008). Light interception and utilization in relay intercrops of wheat and cotton. Field Crops Research, 107(1), 29-42.

Zhu, J., van der Werf, W., Anten, N. P. R., Vos, J., \& Evers, J. B. (2015). The contribution of phenotypic plasticity to complementary light capture in plant mixtures. New Phytologist, 207, 1213-1222.

Zhu, J., van der Werf, W., Vos, J., Anten, N. P. R., van der Putten, P. E. L., \& Evers, J. B. (2016). High productivity of wheat intercropped with maize is associated with plant architectural responses. Annals of Applied Biology, 168(3), 357-372.

Zhu, J., Vos, J., van der Werf, W., van der Putten, P. E. L., \& Evers, J. B. (2014). Early competition shapes maize whole-plant development in mixed stands. Journal of Experimental Botany, 65(2), 641-653.

\section{SUPPORTING INFORMATION}

Additional supporting information may be found online in the Supporting Information section at the end of this article.

How to cite this article: Li S, Evers JB, van der Werf W, et al. Plant architectural responses in simultaneous maize/soybean strip intercropping do not lead to a yield advantage. Ann Appl Biol. 2020;1-16. https://doi.org/10.1111/aab.12610 